\title{
Complications of aortic cannulation for open-heart surgery
}

\author{
J. B. MA G NER \\ Cardiothoracic Unit, Broadgreen Hospital, Liverpool
}

The dangers of femoral and iliac artery cannulation for open-heart surgery are mentioned together with the advantages of using the aorta. Complications associated with the use of an aortic cannula and their recognition and prevention are described.

The performance of open-heart surgery necessitates the cannulation of a major artery to replace, into the patient, blood being returned from the pumpoxygenator. Originally the subclavian artery was used as it was thought that this would ensure good brain and coronary perfusion. With the change to a median sternotomy (Julian, Lopez-Belio, Dye, Javid, and Grove, 1957; Lillehei and Cardozo, 1959) the use of the subclavian artery was abandoned because of the difficulty of access and the danger of destroying the arterial supply to the arm. The femoral (Lillehei and Cardozo, 1959) or iliac (Kirklin and Lyons, 1960) arteries were then used. The use of either of these is associated with many complications, of which the commonest is dissection (Matar and Ross, 1967 ; Elliott and Roe, 1965; Williams and Johnson, 1964 ; Jones, Vetto, Winterscheid, Dillard, and Merendino, 1960). Other complications are retroperitoneal haemorrhage (van der Woude and Iticovicci, 1962), postoperative stenosis and ischaemia, traumatic aneurysm, and late haemorrhage (Baird and Doran, 1964 ; Trimble and Bigelow, 1966). Local dissections can cause paraplegia, steatorrhoea, large bowel obstruction, renal complications, and myocardial infarcts, or they may be a source of emboli or a site for bacterial endocarditis (Matar and Ross, 1967).

Most centres now cannulate the aorta (Nuñez and Bailey, 1959; DeWall and Levy, 1963). This has various advantages-it avoids the complications of femoral artery cannulation, the cannula is continuously visible and easily available to remedy any problems, there is no second operation site of doubtful sterility, time is saved, and in hypothermia the cold blood is directed to the important organs first and to the muscle mass second (DeWall and Levy, 1963). Also a larger cannula can be used which is of importance in children (Nuñez and Bailey, 1959). However, a $\vec{z}$ number of complications from aortic cannulation ฏ have been described. The cannula has entered $\frac{\rho}{\partial}$ the left common carotid artery causing cerebral $\vec{\oplus}$ haemorrhage (Kulkarni, 1968), and Parker (1969) suggests that some postperfusion deaths, especially in children, may be due to inadequate aortic arch perfusion.

Since 1966 there have been 503 cannulations in this unit. The cannula now used is a 7/32 in $(5.6 \mathrm{~mm})$ caval cannula cut diagonally to a point. A cuff of $\frac{1}{4}$ in $(6.4 \mathrm{~mm})$ tubing is placed around it $2 \mathrm{~cm}$ from the end to prevent its entering too far.

In this unit three complications have been seen. The cannula has entered the left subclavian artery, producing a high swinging pressure on the left radiai artery monitor and on the perfusion line pressure gauge in time with the pump. This occurred immediately while the pump output was small. Had the arterial pressure monitor been anywhere other than in the left radial artery then recognition of the cannulation of an arch vessel $\frac{}{\partial}$ would be made by a sharp fall in arterial pressure $\rightarrow$ combined with a high line pressure reading on the pump-oxygenator. Inadvertent innominate artery $N$ cannulation might produce disastrous effects on the brain if recognition were not immediate. 0 These complications can be prevented by using $\mathrm{C}$ an aortotomy low in the ascending aorta and placing only $2 \mathrm{~cm}$ length of cannula in the aorta. Vigilance is needed during the early stages of $\mathbb{D}$ bypass to notice the signs mentioned; if they ?+?

occur the cannula is repositioned.
The second complication occurs when the $\frac{0}{\mathbb{0}}$ cannula swings and the tip lies close to or through $\stackrel{\odot}{\odot}$ the aortic valve. Both have been seen. If the $\stackrel{\varnothing}{\Omega}$ tip passes through the aortic valve the heart? distends grossly when the pump is started and $\delta$ 
at the same time the arterial pressure falls steeply. If a left ventricular drain is then inserted the output of the pump shunts back to the machine via the drain and does not oxygenate the patient. If the cannula lies close to the aortic valve, pointing at the valve, there will be turbulence and also the flow has to get back past the cannula to get down the aorta. Another danger is that the cannula may be clamped if an aortic clamp is applied. This will cause a steep pressure rise in the machine and may burst the tubes or cause leaks if it is not noticed immediately. Also it cuts off the supply of blood to the patient. The use of only a short length of cannula inside the aorta combined with careful placement will prevent these complications.

The use of too large or too long a cannula may create problems. If the tip of the cannula lies distal to the origins of the innominate or left common carotid artery then perfusion of these vessels may be poor, either by partial blocking of the openings by the cannula or the Venturi effect of the jet of blood from the tip of the cannula reducing the pressure behind it. The use of a cannula as described by Parker (1969) may be helpful. The use of too large a cannula in a small aorta can also cause problems at the end of the perfusion. A recent case caused some anxiety at the end of perfusion as the blood pressure failed to rise above $50 \mathrm{mmHg}$ even when assisted by a rise of the venous pressure and an isoprenaline drip. It was then realized that the cannula itself was acting as an obstruction and its removal raised the systolic pressure to $90 \mathrm{mmHg}$ immediately ; progressive improvement followed. If it is suspected that a large cannula is causing hypotension then a pressure gradient should be demonstrable across it.

There have been no cases of haemorrhage from the cannulation or sepsis at the cannulation site.

\section{CONCLUSIONS}

In this unit the aorta is considered to be the best site for cannulation but care is needed to avoid complications. They can be avoided by careful placement of the cannula and vigilance on starting the perfusion.

I wish to thank Dr. J. C. Richardson and Mr. L. J. Temple for help in the preparation of this paper.

\section{REFERENCES}

Baird, R. J., and Doran, M. L. (1964). The false aneurysm. Canad. med. Ass. J., 91, 281.

DeWall, R. A., and Levy, M. J. (1963). Direct cannulation of the ascending aorta for open-heart surgery. $J$. thorac. cardiovasc. Surg., 45, 496.

Elliott, D. P., and Roe, B. B. (1965). Aortic dissection during cardiopulmonary bypass. J. thorac. cardiovasc. Surg., 50, 357.

Jones, T. W., Vetto, R. R., Winterscheid, L. C., Dillard, D. H., and Merendino, K. A. (1960). Arterial complications incident to cannulation in open-heart surgery. Ann. Surg., 152, 969.

Julian, O. C., Lopez-Belio, M., Dye, W. S., Javid, H., and Grove, W. J. (1957). The medial sternal incision in intracardiac surgery with extracorporeal circulation: a general evaluation of its use in heart surgery. Surgery, 42, 753.

Kirklin, J. W., and Lyons, W. S. (1960). Arterial cannulation for extracorporeal circulation utilizing the external or common iliac artery. Surgery, 47, 648.

Kulkarni, M. G. (1968). Case report: a complication of aortic cannulation. J. cardiovasc. Surg. (Torino), 9, 207.

Lillehei, C. W., and Cardozo, R. H. (1959). Use of median sternotomy with femoral artery cannulation in open cardiac surgery. Surg. Gynec. Obstet., 108, 707.

Matar, A. F., and Ross, D. N. (1967). Traumatic arterial dissection in open-heart surgery. Thorax, $22,82$.

Nuñez, L. E., and Bailey, C. P. (1959). New method for systemic arterial perfusion in extracorporeal circulation. J. thorac. Surg., 37, 707.

Parker, R. (1969). Aortic cannulation. Thorax, 24, 742.

Trimble, A. S., and Bigelow, W. G. (1966). Proximal aortic cannulation for extracorporeal circulation. $J$. thorac. cardiovasc. Surg., 51, 674.

van der Woude, R., and Iticovicci, H. (1962). Retroperitoneal hemorrhage as a complication of femoral artery cannulation for extracorporeal circulation; a case report. J. thorac. cardiovasc. Surg., 44, 540.

Williams, K. R., and Johnson, J. (1964). Aortic dissection after femoral artery cannulation. Arch. Surg., 89, 663. 